\title{
Stability Study of Fluconazole Applying Validated Bioassay and Stability- Indicating LC Methods
}

Josilene Chaves Ruela Corrêa ${ }^{1 *}$, Camila Reichman ${ }^{1}$, Cristina Duarte Vianna-Soares² and Hérida Regina Nunes Salgado ${ }^{1}$

${ }^{1}$ Drugs and Medicines Quality Control Laboratory, School of Pharmaceutical Sciences, University Estadual Paulista, Rodovia Araraquara-Jaú, km 1, 14801-902, Araraquara, Brazil

${ }^{2}$ Department of Pharmaceutical Products, Federal University of Minas Gerais, Av. Pres. Antônio Carlos, 6627, 31270-901, Belo Horizonte, Brazil

\begin{abstract}
Chemical degradation of drugs may result in altered therapeutic efficacy and even toxic effects. Therefore, understanding the factors that change the stability of pharmaceuticals and identifying ways to guarantee their stability are important. In this work stability-indicating Liquid Chromatographic (LC) and bioassay methods were validated and employed in the fluconazole stability studies. The correlation of sample results from both methods was evaluated. Fluconazole raw material stability was investigated in aqueous, acid $(0.1 \mathrm{M} \mathrm{HCl})$, alkaline $(0.1 \mathrm{M}$ $\mathrm{NaOH})$ and oxidative $\left(3 \% \mathrm{v} / \mathrm{v} \mathrm{H}_{2} \mathrm{O}_{2}\right)$ reflux for 6 hours, by LC method. Fluconazole capsules were exposed to UVC (254 nm, 66 and 180 days), climatic chamber $\left(40^{\circ} \mathrm{C}, 75 \% \mathrm{RH}, 90\right.$ days) and oven $\left(60^{\circ} \mathrm{C}, 60\right.$ days), these samples were analyzed by LC and bioassay methods It was found that the drug is degraded (10\% decrease) with arising of a possible degradation product in an oxidative medium and UVC exposure, in all the others conditions fluconazole remained chemically stable (higher than $98 \%$ ) when analyzed by LC. However when the capsules stressed samples were evaluated through bioassay very low antifungal activity was found (about $30 \%$ ). Fluconazole showed to be an unstable drug and it indicates that special care must be taken during the handling, storage and quality control using appropriated methods to analyze this therapeutic agent. This work suggests monitoring the fluconazole stability by bioassay and the stability-indicating LC methods.
\end{abstract}

Keywords: Fluconazole; Stability studies; Stability-indicating method; Liquid chromatography; Bioassay

\section{Introduction}

Stability is defined as the capacity of a drug substance or product to remain within established specifications and to maintain its identity, strength, quality, and purity throughout expiration dating period. Pharmaceuticals are especially sensitive to environmental factors. Strict storage conditions are necessary for the maintenance of integrity and product activity [1]. Stability test of an active substance or drug product can provides evidence on the drug quality and if it can be influenced by a variety of environmental factors such as temperature, humidity and light [1].

Chemical and physical degradation of drugs may result in altered therapeutic efficacy and even toxic effects. Therefore, understanding the factors that change the stability of pharmaceuticals and identifying ways to guarantee their stability are important [2].

In recent years the investigation about the influence of light on the stability of drugs has gained more and more importance. Information about photostability of drugs can help to determine the storage

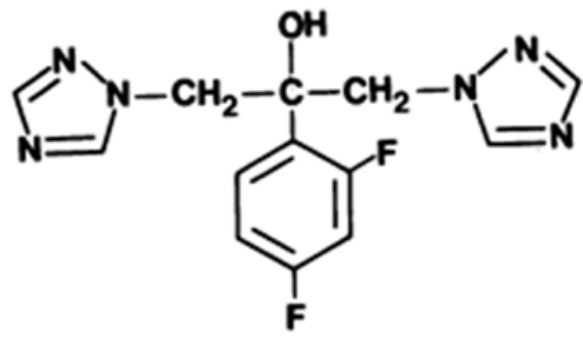

Figure 1: Fluconazole chemical structure (CAS 86386-73-4) conditions in order to remain high quality of pharmaceutical products [3].

Fluconazole, $\alpha$-(2,4-diflurophenyl)- $\alpha$-(1H-triazole-1-methyl)- $1 \mathrm{H}$ 1,2,4-triazole-1-ethanol (Figure 1), is a broad spectrum antifungal agent. It is indicated for the treatment of superficial, cutaneous and cutaneo-mucous infections caused by Candida species.

Fluconazole is a first generation triazole. Synthesized in 1982, the drug is a polar bis-triazole and it is less lipophilic than the other azoles (e.g. ketoconazole, itraconazole, miconazole) [4]. The presence of a halogen-phenyl group increases its antifungal activity and aqueous solubility, leading to higher bioavailability. In addition, its high metabolic stability was achieved by association of three structural features: the strength of the triazole ring to oxidative attack, the blockage of aromatic hydroxylation by the presence of two fluorine atoms and the steric hindrance of the hydroxyl site from a possible combination [5-7].

A search about the stability of fluconazole was carried out. Few stability studies were found in the literature and they were related to fluconazole stability in infusion solutions and raw material. Dentinger

*Corresponding author: Drugs and Medicines Quality Control Laboratory, Schoo of Pharmaceutical Sciences, University Estadual Paulista, Brazil, Tel: +55 163301 4681; E-mail: josilenechavescorrea@gmail.com

Received October 16, 2011; Accepted November 29, 2011; Published December 02, 2011

Citation: Corrêa JCR, Reichman C, Soares CDV, Salgado HRN (2011) AStability Study of Fluconazole Applying Validated Bioassay and Stability-Indicating LC Methods. J Anal Bioanal Techniques 2:126. doi:10.4172/2155-9872.1000126

Copyright: (c) 2011 Corrêa JCR. This is an open-access article distributed under the terms of the Creative Commons Attribution License, which permits unrestricted use, distribution, and reproduction in any medium, provided the original author and source are credited. 
Citation: Corrêa JCR, Reichman C, Soares CDV, Salgado HRN (2011) AStability Study of Fluconazole Applying Validated Bioassay and StabilityIndicating LC Methods. J Anal Bioanal Techniques 2:126. doi:10.4172/2155-9872.1000126

Page 2 of 6

\& Swenson [8] and Yamreudee wong \& Lopez-Anaya [9] have showed that fluconazole injectable solution can be stable for several days if the samples were stored at controlled temperature $\left(22-45^{\circ} \mathrm{C}\right)$. Marciniec and coworkers [10] have showed that fluconazole raw material is unstable when sterilized using ionizing radiation. The researchers observed that irradiated samples showed increased absorption in UV region. The instability under other degradation conditions remains unknown. There are many published analytical method to determine fluconazole [11], however there is no a bioassay method to evaluate the fluconazole stability.

The aims of this study were verifying the drug stability under stress conditions and quantify it by validated bioassay and Liquid Chromatographic (LC) stability-indicating methods.

\section{Material and Methods}

\section{Chemicals}

Fluconazole chemical reference (assigned purity of 100\%) was obtained from Sigma Aldrich, fluconazole raw material was kindly donated by EMS (Campinas, Brazil). It was standardized against fluconazole chemical reference. Capsules were purchased from local markers with label of $150 \mathrm{mg}$ of drug.

Methanol LC grade was purchased from Tedia (Fairfield, USA). Ultrapurified water was prepared in-house by using Direct- $Q^{\oplus}$ water system (Millipore Corporation, Billerica, USA). Prior to use, mobile phase solvents were degassed in an ultrasonic bath for $30 \mathrm{~min}$. Sodium hydroxide, hydrochloric acid, and hydrogen peroxide (reagent grade) were purchased from Merck (Darmstadt, Germany). Purified water $(<18<\mathrm{mu}>\mathrm{S})$ was used to prepare the mobile phase, the sample and the standard solutions. Solvents were filtered through a $0.45 \mu \mathrm{m}$ membrane filter.

\section{Apparatus}

Liquid Chromatography apparatus (Waters Corporation, Milford, MA, USA), equipped with a Waters 1525 binary pump, a Rheodyne Breeze 7725i manual injector, a Waters 2487 UV-VIS wavelength detector was used. In addition a Liquid Chromatography apparatus Shimadzu ${ }^{\circ}$ CLASS-VP, with PDA detector (Shimadzu Corporate, Japan) was employed. HPLC analysis was conducted by using a RP C18 column (Symmetry Waters, Milford, MA, USA), with $5 \mu \mathrm{m}$ particle size, $4.6 \mathrm{~mm}$ x $250 \mathrm{~mm}$.
Oven (FABBE ${ }^{\oplus}$ Ltda), climatic chamber (Marconi ${ }^{\oplus}$, MA 835/UR) and a UVC chamber were used to perform the stress conditions.

\section{Validation of methods}

Both LC and bioassay methods were validated according to the International Conference on Harmonization ( $\mathrm{ICH}$ ) guidelines [12]. The following characteristics were considered for validation: specificity, linearity, range, accuracy and precision. Specificity was evaluated by comparison of chromatograms of samples containing possible interfering substances (excipient products used in capsules production) and samples containing fluconazole.

Linearity was determined in the range 240 to $1200 \mu \mathrm{g} / \mathrm{mL}$ (LC method) and 25 to $100 \mu \mathrm{g} / \mathrm{mL}$ (bioassay). To calculation of regression from the peak area vs. concentration of standard solutions (they were prepared as explained in the items number 2.3 and 2.4) the least square methodology was used.

Accuracy was tested by calculating the percentage recoveries of fluconazole from sample solutions (they were prepared as explained in the items number 2.3 and 2.4) at different concentrations and by determining the relative standard deviation (RSD). Precision was assessed at different levels - repeatability (system repeatability by testing three curves constructed with five different standard solution concentrations, in the same day); and intermediate (by analyzing three different standard solution concentrations high, intermediate and low, in a different day, with two days interval between repeatability and intermediate). Standard solutions prepared as was explained in the items number 2.3 and 2.4 were used to assess the precision of the methods. Robustness was evaluated by Youden \& Steiner method [13]. By this method seven different parameters could be evaluated by eight analyses employing factorial combination.

\section{LC conditions}

Chromatographic analysis was performed in isocratic mode. Mobile phase consists of methanol-water $(60: 40, \mathrm{v} / \mathrm{v})$ at a flow rate of 1 $\mathrm{mL} / \mathrm{min}$. The injection volume was $20 \mu \mathrm{L}$ and the detection wavelength was $261 \mathrm{~nm}$. Total run time was $5 \mathrm{~min}$. All experiments were performed at room temperature $\left(25^{\circ} \mathrm{C}\right)$ and the total area of peak was used to quantify fluconazole.

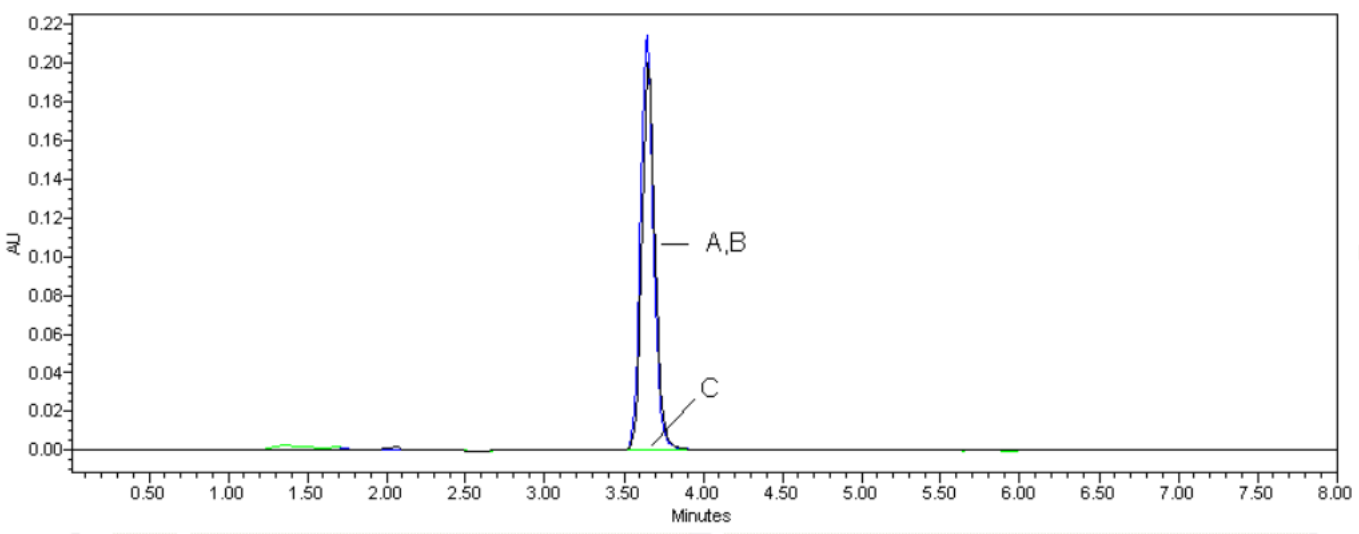

Figure 2: Overlay chromatograms for fluconazole RS (A), fluconazole capsules (B) and its placebo (C). Fluconazole dilution equivalent (600 $\mu$ g/mL) chromatogram 
Citation: Corrêa JCR, Reichman C, Soares CDV, Salgado HRN (2011) AStability Study of Fluconazole Applying Validated Bioassay and StabilityIndicating LC Methods. J Anal Bioanal Techniques 2:126. doi:10.4172/2155-9872.1000126

Page 3 of 6

\section{Preparation of standard and sample solutions to validate the LC method}

Fluconazole standard stock solution was prepared by dissolving $125 \mathrm{mg}$ of standard accurately weighted in $100 \mathrm{~mL}$ volumetric flask. Fluconazole was solubilized with $5 \mathrm{~mL}$ methanol and $60 \mathrm{~mL}$ water. It was kept in ultrasonic bath for $30 \mathrm{~min}$, and the volume was making up to volume with water. Further diluting to volume with same solvent six final concentrations were obtained: $240,360,480,600,900$ and 1200 $\mu \mathrm{g} / \mathrm{mL}$.

To prepare the sample solution, 20 fluconazole capsules were weighed and its powder mixed making a pool. A quantity equivalent to $125 \mathrm{mg}$ of fluconazole was transferred into a $100 \mathrm{~mL}$ volumetric flask with $5 \mathrm{~mL}$ methanol and $60 \mathrm{~mL}$ water, kept in ultrasonic bath for $30 \mathrm{~min}$, and the volume was completed with water. The final six concentrations were made at the same way of standard solutions. Placebo solution was prepared at the same form

\section{Bioassay conditions}

The diffusion method employed two agar layers (Sabouraud 2\% agar) with only the upper one inoculated with a standard suspension of Candida albicans ATCC 90028 ( $25 \pm 2 \%$ of transmittance at 580 $\mathrm{nm}$ ), at $2 \%$ concentration. After the agar solidified, six stainless steel cylinders size uniformed ( $8 \mathrm{~mm} \times 6 \mathrm{~mm} \times 10 \mathrm{~mm})$ were placed on the surface of the inoculated medium in each Petri dish. Aliquots $(100 \mu \mathrm{L})$ of fluconazole reference substance at concentrations of 25, 50 and 100 $\mu \mathrm{g} / \mathrm{mL}$, according to $3 \times 3$ assay, were added to three cylinders and 100 $\mu \mathrm{L}$ of the degraded samples at the same concentrations were added to the other three cylinders (Figure 3).

After incubation $\left(25^{\circ} \mathrm{C}\right.$ for $\left.24 \pm 1 \mathrm{~h}\right)$, the antifungal activity was estimated based on the diameters of the microorganism growth inhibition zone $(\mathrm{mm})$ promoted by degraded samples and by the reference substance. The inhibition zones were measured using an electronic digital caliper (Starrett ${ }^{\circ}$, USA). Each degraded sample was assayed three times, using six plates in each assay. The percentage activity of fluconazole solutions was calculated by Hewitt equations [14]. The assay was statistically calculated by linear parallel model and by means of regression analysis, being then verified using analysis of variance (ANOVA).

\section{Preparation of standard and sample solutions to validate the bioassay method}

Fluconazole stock solution was prepared by dissolving $6.24 \mathrm{mg}$ of accurately weighted drug in $25 \mathrm{~mL}$ volumetric flask dissolved with $15 \mathrm{~mL}$ water and kept in ultrasonic bath for $30 \mathrm{~min}$. The volume was completed with water and further diluting to volume with same solvent to give three final concentrations: 25,50 and $100 \mu \mathrm{g} / \mathrm{mL}$.

To prepare the sample solution, 20 fluconazole capsules were weighed and its powder mixed making a pool. A quantity equivalent to $6.24 \mathrm{mg}$ of fluconazole was transferred into a $25 \mathrm{~mL}$ volumetric flask with $15 \mathrm{~mL}$ water and kept in ultrasonic bath for $30 \mathrm{~min}$. The volume was completed with water and the three final concentrations were made at the same way of standard solutions.

\section{Stability study}

Hydrolysis (acid, alkaline, neutral and oxidative media): Sample solutions were prepared at concentration of $1 \mathrm{~g} / \mathrm{mL}$ in water, $0.1 \mathrm{M}$ $\mathrm{HCl}, 0.1 \mathrm{M} \mathrm{NaOH}, 3 \% \mathrm{H}_{2} \mathrm{O}_{2}$, they were stored at room temperature for $1 \mathrm{~h}$, or they were stored for 2,4 and $6 \mathrm{~h}$ at $90^{\circ} \mathrm{C}$ in reflux. After that,

\begin{tabular}{|l|l|l|}
\hline Parameters & LC & Bioassay \\
\hline Useful concentration, $\mu \mathrm{g} / \mathrm{mL}$ & 600 & $25 ; 50$ and 100 \\
\hline Analytical curve & $5.334 \mathrm{X}+2.084$ & $11.76 \mathrm{X}-1.358$ \\
\hline Determination coefficient $\left(\mathrm{r}^{2}\right)$ & 0.9997 & 0.9984 \\
\hline R.S.D. of Repeatability $(\%)$ & 0.43 & 4.34 \\
\hline R.S.D. intermediate precision (\%) & 1.96 & 6.15 \\
\hline Accuracy (\%) & 101.06 & 97.30 \\
\hline RSD of accuracy (\%) & 0.69 & 5.98 \\
\hline
\end{tabular}

Table 1: Validation parameters for LC and bioassay methods for fluconazole capsules

\begin{tabular}{|l|l|l|l|}
\hline Method & Added amount $(\mu \mathrm{g} / \mathrm{mL})$ & Found $^{\mathrm{a}}$ amount $(\%)$ & Recovery $^{\mathrm{a}}(\%) \pm$ R.S.D. \\
\hline HPLC & 240.00 & 242.33 & $100.97 \pm 0.52$ \\
\hline & 360.00 & 360.86 & $100.24 \pm 0.43$ \\
\hline & 480.00 & 487.01 & $101.47 \pm 0.26$ \\
\hline & 600.00 & 610.14 & $101.69 \pm 0.34$ \\
\hline & 900.00 & 907.74 & $100.86 \pm 0.66$ \\
\hline & 1200.00 & 1216.44 & $101.37 \pm 0.45$ \\
\hline Bioassay & 25.00 & 24.24 & $96.95 \pm 6.66$ \\
\hline & 50.00 & 48.48 & $96.96 \pm 6.13$ \\
\hline & 100.00 & 97.98 & $97.98 \pm 5.15$ \\
\hline
\end{tabular}

aMean of three replicates

Table 2: Recovery data of standard solutions added to the placebo analyzed by using the proposed LC and bioassay methods

\begin{tabular}{|l|l|l|l|l|l|l|l|l|}
\hline Parameter & \multicolumn{70}{|c|}{ Factorial combination } \\
\hline & 1 & 2 & 3 & 4 & 5 & 6 & 7 & 8 \\
\hline A, a & A & A & A & A & A & a & a & a \\
\hline B,b & B & B & b & b & B & B & B & b \\
\hline C,c & C & C & C & c & C & C & C & c \\
\hline D,d & D & D & d & d & D & D & D & D \\
\hline E,e & E & e & E & e & E & E & E & E \\
\hline F,f & F & f & f & F & F & F & F & F \\
\hline G,g & G & g & g & G & G & G & G & g \\
\hline Results & S & $t$ & u & V & X & y & W & z \\
\hline
\end{tabular}

Table 3: Factorial combination to Youden \& Steiner test (Youden \& Steiner, 1975)

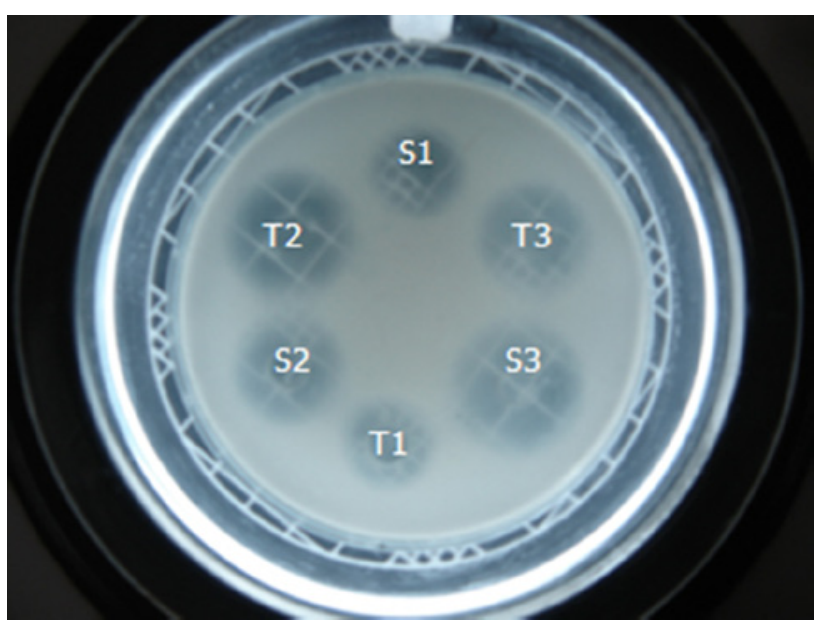

Figure 3: Design $3 \times 3$, demonstration the standard solution (S) and sample solutions $(T)$ disposed in Petri dishes, where S1 $=25 \mu \mathrm{g} / \mathrm{mL}, \mathrm{S} 2=50 \mu \mathrm{g} / \mathrm{mL}$, S3 $=100 \mu \mathrm{g} / \mathrm{mL} ; \mathrm{T} 1=25 \mu \mathrm{g} / \mathrm{mL}, \mathrm{T} 2=50 \mu \mathrm{g} / \mathrm{mL}, \mathrm{T} 3=100 \mu \mathrm{g} / \mathrm{mL}$

aliquots of these solutions were removed, neutralized and diluted in water to achieve theoretical concentration, $500 \mu \mathrm{g} / \mathrm{mL}$. These samples were evaluated by LC method. 
Citation: Corrêa JCR, Reichman C, Soares CDV, Salgado HRN (2011) AStability Study of Fluconazole Applying Validated Bioassay and StabilityIndicating LC Methods. J Anal Bioanal Techniques 2:126. doi:10.4172/2155-9872.1000126

Page 4 of 6

In addition, sample solutions were prepared in water at concentration of $1 \mathrm{~g} / \mathrm{mL}$, and were exposed to UVC radiation $(254 \mathrm{~nm})$ for $1 \mathrm{~h}$. The stress degradation was carried out exposing the solutions in flasks. Control samples protected from light with aluminum foil were also placed in exposition concurrently in the light chamber. After that, aliquots of these solutions were removed and diluted in water to achieve theoretical concentration $500 \mu \mathrm{g} / \mathrm{mL}$. These samples were evaluated by LC method.

\section{Fluconazole solid form stress testing}

Thermal degradation: The powder of the pool of capsules and the placebo were maintained at $60^{\circ} \mathrm{C}$ in a dry air oven for $7,14,21,32,45$ and 60 days, or they were maintained at $40^{\circ} \mathrm{C}, 75 \%$ relative humidity for $14,21,30,60$ and 90 days in a climatic chamber. After that, aliquots of these powders were removed and diluted in water to achieve theoretical concentrations of $500 \mu \mathrm{g} / \mathrm{mL}$ (LC method) and 25, 50 and $100 \mu \mathrm{g} / \mathrm{mL}$ (bioassay). These samples were evaluated.

Photodegradation: The powder of the pool of capsules and excipients were exposed to UVC radiation $(254 \mathrm{~nm})$ for $21,33,66$ and 180 days in a photodegradation chamber. The stress degradation was carried out exposing the powders in opened Petri dishes. After that, aliquots of these powders were removed and diluted in water to achieve theoretical concentrations $500 \mu \mathrm{g} / \mathrm{mL}$ (LC method) and 25, 50 and $100 \mu \mathrm{g} / \mathrm{mL}$ (bioassay). These samples were evaluated by LC and bioassay methods.

\section{Results and Discussion}

\section{Validation of LC method}

LC is a separation method widely used in stability studies. It is applied as an indicating stability method when it is able to split degradation products. The $\mathrm{LC}$ method validated is fast (retention time, $3.7 \mathrm{~min}$ ) and optimized method. Good symmetry was obtained by using end capped column and mix of methanol and water $(60: 40, \mathrm{v} / \mathrm{v})$ as mobile phase. The chromatograms of standard fluconazole solutions, sample solutions and its placebo are shown in Figure 2.

The precision of the method was determined by repeatability (intraday) and intermediate precision (inter-day) and was expressed as R.S.D.
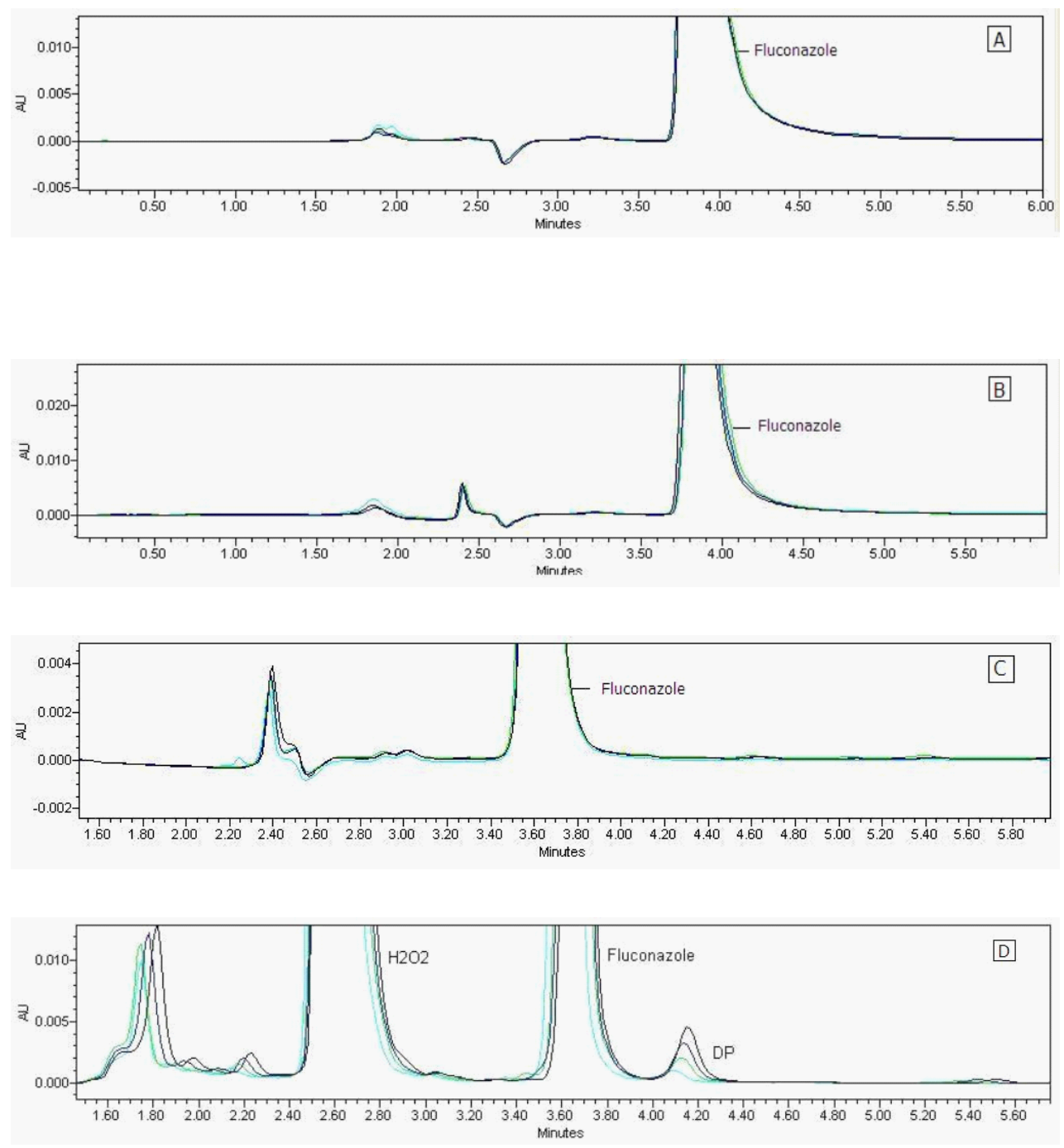

Figure 4: Overlay chromatograms obtained from aqueous (A), acid (B), alkaline (C) and oxidative (D) stress sample heated for 30 minutes, 2,4 and 6 hours. A possible degradation product (DP) in oxidative stress is shown. 
Citation: Corrêa JCR, Reichman C, Soares CDV, Salgado HRN (2011) AStability Study of Fluconazole Applying Validated Bioassay and StabilityIndicating LC Methods. J Anal Bioanal Techniques 2:126. doi:10.4172/2155-9872.1000126
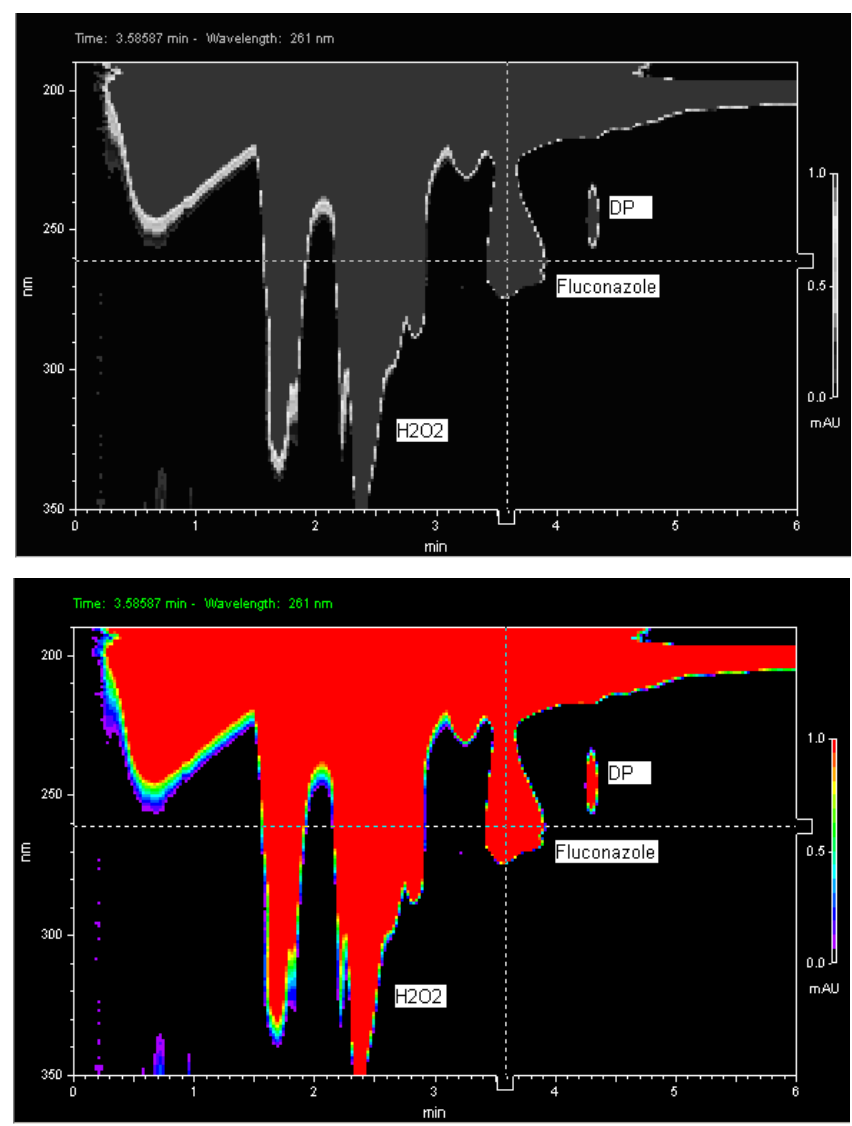

Figure 5: UV bidimensional chromatogram of fluconazole work standard prepared in $\mathrm{H} 2 \mathrm{O} 23 \% \mathrm{v} / \mathrm{v}(500 \mathrm{mg} / \mathrm{mL})$ after 6 hours of heating at $90^{\circ} \mathrm{C}$ under reflux. Diode array detector was employed.

(\%) of a series of measurement. The result obtained shows R.S.D. from 0.14 to $0.81 \%$, mean $0.43 \%$, indicating good intra-day precision. Interday variability was calculated from assays on 3 days and shows a mean R.S.D. of $1.96 \%$ (Table 1). The accuracy of the method was determined by the mean recovery. The mean result was $101.06 \%$ (Tables 1 and 2) indicating an agreement between the true value and the value found.

Robustness testing is useful in order to prove that typical variations to the method are negligible in the procedure outcome, being usually studied by deliberately changing critical parameters and monitor possible alterations. A method is said to be robust when these alterations produce no significant changes in its results.

The robustness test by Youden \& Steiner method [13] can evaluate the interference of low and deliberated changes in seven parameters on the fluconazole content. The parameters evaluated were: chromatographic column $(\mathrm{A} / \mathrm{a})$, wavelength $(\mathrm{B} / \mathrm{b})$, flow rate $(\mathrm{C} / \mathrm{c})$, mobile phase $(\mathrm{D} / \mathrm{d})$, injection volume $(\mathrm{E} / \mathrm{e})$, oven temperature $(\mathrm{F} / \mathrm{f})$ and shaking time $(\mathrm{G} / \mathrm{g})$. Table 3 shows the factorial combination of analytical parameters evaluated.

To evaluate the effect of each variation on the fluconazole assay the following equation was used [15].

$$
\mathrm{A}, \mathrm{a}=(x+y+w+z) / 4-(s+t+u+v) / 4 \text { (Equation to parameter } \mathrm{A}, \mathrm{a})
$$

The major effect on the fluconazole content was obtained with parameter G, g (4.74\%). Therefore agitation time should be obeyed

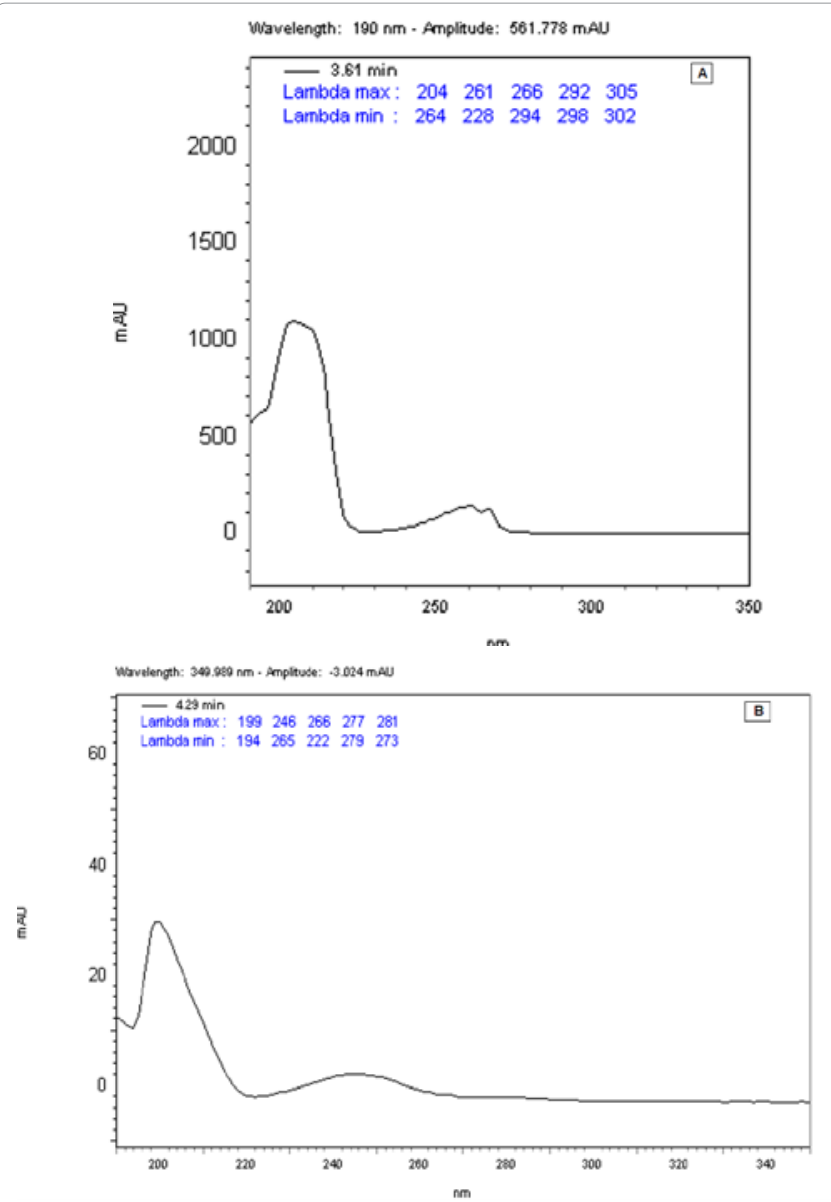

Figure 6: UV absorption spectrum of fluconazole at $500 \mu \mathrm{g} / \mathrm{mL}(\mathrm{A})$ and fluconazole degradation product in fluconazole solution at $500 \mu \mathrm{g} / \mathrm{mL}$ (B) with indication of maximum and minimum lengths of absorbance.

rigorously. The results to others parameters show that few and unintentional changes do not effect the test.

\section{Validation of bioassay method}

In accordance with Paim and coworkers [16] "The potency of an antibiotic may be demonstrated under suitable conditions by comparing the growth inhibition of sensitive microorganisms produced by known concentrations of the antibiotic to be examined and a reference standard. Impurities and related substances do not interfere, maintaining the precision of the analytical method. Therefore, microbial or biological assays remain, in general, the standard for dispelling doubts about the potential loss of activity." This declaration is, absolutely, in agreement with the US Pharmacopeia [17].

In this study three dose levels $(25,50$ and $100 \mu \mathrm{g} / \mathrm{mL})$ of standard and sample solutions, prepared as was explained in the item 2.4, were used following the procedure described in the Brazilian [18] and European Pharmacopoeias [19]. The Figure 3 shows the concentration scheme used in diffusion method.

The signals S3, S2 e S1 refer to diameter of inhibition zones from standard solutions and T3, T2 e T1 refer to diameter of inhibition zones from samples solutions with high, medium and low concentration, respectively.

This procedure has assumed a direct relationship between the 


\begin{tabular}{|c|c|c|c|}
\hline Stress conditions & $\begin{array}{c}\text { New peaks } \\
\left(\mathrm{Rt}^{\mathrm{a}} ; \mathrm{R}^{\mathrm{b}}\right)\end{array}$ & $\begin{array}{c}\text { Fluconazole } \\
\mathrm{Rt}^{\mathrm{a}}(\mathrm{min})\end{array}$ & $\begin{array}{c}\text { Recov- } \\
\text { ery }(\%)\end{array}$ \\
\hline- & - & 3.70 & 100.00 \\
\hline water, $1 \mathrm{~h}$ & No & 3.71 & 98.15 \\
\hline $\mathrm{HCl} 0.1 \mathrm{M}, 1 \mathrm{~h}$ & No & 3.83 & 99.02 \\
\hline $\mathrm{NaOH} 0.1 \mathrm{M}, 1 \mathrm{~h}$ & No & 3.62 & 100.00 \\
\hline $\mathrm{H}_{2} \mathrm{O}_{2} \%$ ( $\left./ \mathrm{v} / \mathrm{v}\right), 1 \mathrm{~h}$ & No & 3.67 & 94.13 \\
\hline $\mathrm{UVC}$ light, $1 \mathrm{~h}$ & No & 3.69 & 100.00 \\
\hline $\mathrm{UVC}$ light, $24 \mathrm{~h}$ & No & 3.69 & 100.00 \\
\hline Water at $90^{\circ} \mathrm{C}$, reflux, $6 \mathrm{~h}$ & No & 3.71 & 100.00 \\
\hline $\mathrm{HCl} 0.1 \mathrm{M}$ at $90^{\circ} \mathrm{C}$, reflux, $6 \mathrm{~h}$ & No & 3.86 & 100.00 \\
\hline $\mathrm{NaOH} 0.1 \mathrm{M}$ at $90^{\circ} \mathrm{C}$, reflux, $6 \mathrm{~h}$ & No & 3.67 & 101.84 \\
\hline $\mathrm{H}_{2} \mathrm{O}_{2} 3 \%(\mathrm{v} / \mathrm{v})$ at $90^{\circ} \mathrm{C}$, reflux, $6 \mathrm{~h}$ & $(4,18 ; 1,58)$ & 3.65 & 90.12 \\
\hline
\end{tabular}

aRt: retention time. ${ }^{\mathrm{b}} \mathrm{R}$ : resolution

Table 4: Chromatogram information and recovery of fluconazole solutions ( $500 \mu \mathrm{g} /$ $\mathrm{mL}$ ) after stress testing.

\begin{tabular}{|l|l|l|l|l|}
\hline \multirow{2}{*}{ Stress conditions } & \multicolumn{2}{|c|}{ LC } & \multicolumn{2}{c|}{ Bioassay } \\
\cline { 2 - 5 } & Content(\%) & RSD $^{\mathrm{a}}(\%)$ & Potency(\%) & RSD $\left.^{\mathrm{a}} \%\right)$ \\
\hline Humid heat, 90 days & 95.36 & 1.97 & 36.99 & 2.17 \\
\hline Dry heat, 60 days & 97.45 & 0.31 & 34.50 & 10.17 \\
\hline UVC, 66 days & 95.37 & 1.85 & 25.73 & 13.56 \\
\hline UVC, 180 days & 95.91 & 0.44 & 33.39 & 3.91 \\
\hline
\end{tabular}

aRSD: relative standard deviation

Table 5: Content of fluconazole solid state stress using LC and bioassay methods.

\begin{tabular}{|c|c|c|c|}
\hline Conditions & $\begin{array}{c}\text { Time exposure } \\
\text { (days) }\end{array}$ & Absorption/ $\mu \mathrm{g}$ & $\begin{array}{c}\text { Absorption increased } \\
\text { related to standard (\%) }\end{array}$ \\
\hline Standard & - & 0.507407 & - \\
\hline UVC light & 66 & 0.661487 & 130.37 \\
\hline & 90 & 0.629214 & 124.01 \\
\hline & 120 & 0.690127 & 136.01 \\
\hline & 150 & 0.678960 & 133.81 \\
\hline & 180 & 0.641940 & 126.51 \\
\hline Dry heat & 60 & 0.571536 & 112.64 \\
\hline Humid heat & 90 & 0.557995 & 109.97 \\
\hline
\end{tabular}

Table 6: Absorbance of fluconazole stress testing samples per weight unit and fluconazole standard $(500 \mu \mathrm{g} / \mathrm{mL})$ at $261 \mathrm{~nm}$.

observed zone diameter and the logarithm of the applied dose, the parallel-line model was chosen. The two log dose-response lines of the preparations to be examined as well as the reference preparation showed being parallel and linear between 25 and $100 \mu \mathrm{g} / \mathrm{mL}$. The representative linear equation was $y=11.76 x-1.358\left(r^{2}=0.9984\right)$, where $\mathrm{x}$ is the $\log$ concentration and $\mathrm{y}$ is the diameter of the inhibition zone (Table 1).

The range of doses used was verified by validity tests by means of ANOVA, no deviation from parallelism and linearity was found $(\mathrm{p}>$ $0.05)$, and the regression was statistically significant $(\mathrm{p}<0.05)$.

The precision of the method was determined by repeatability (intra-day) and intermediate precision (inter-day) and was expressed as R.S.D. (\%) of a series of measurement. The result obtained shows R.S.D. of $4.34 \%$ (Table 2). Inter-day variability was calculated from assays on 3 days and shows a mean R.S.D. of $6.15 \%$ (Table 1). The mean recovery found was equal to $97.30 \%$ (Table 2). This method shows good agreement between the true value and the value found.

\section{Stability study}

Hydrolysis (acid, alkaline, neutral and oxidative media): In order to obtain information about the stability the drug was submitted to forced degradation studies to induce its degradation. Stress testing of a drug can help to identify the probable degradation products, which can be useful to establish the degradation pathways and the intrinsic stability of the molecule and also to validate the stability-indicating power of the analytical procedures [20].

Fluconazole raw material was under stress conditions and this sample analyzed by validate LC using PDA detector (Figure 4 A-D) showed content decreased about $1 \%$ in acid, $2 \%$ in water and $6 \%$ in oxidative medium at room temperature; $10 \%$ in oxidative medium at heating. Only oxidative solution after heating showed a new peak (Table 4). It can indicate a possible degradation product (Figure 4-D). The drug showed to have a good stability in these studied conditions.

The chromatogram of oxidative stress sample under $90^{\circ} \mathrm{C}$ for 30 minutes, 2, 4 and 6 hours is shown in the Figure 4-D.

This LC method was able separate the fluconazole and its possible degradation product. These peaks were measured by PDA detector and they proved to be totally separated (Figure 5). It is possible to observe the differences between the absorption spectra in the UV region of fluconazole and its possible degradation product in the Figure 6 (A-B).

\section{Fluconazole solid form stress testing}

Powder of fluconazole capsules and its placebo were under stress conditions: dry heat, humid heat and UVC light. These samples were analyzed by validate bioassay and LC methods. The results from diffusion method showed fluconazole as a not stable drug presenting low activity after stress testing. Table 5 shows the results from fluconazole solid state stress testing by LC and bioassay methods.

The results from both methods were significantly different. Fluconazole showed high instability with decrease of its antifungal activity in all conditions it was employed using the bioassay; however it shows high stability when analyzed by LC. Many aspects can be responsible for this fact. During stability studies several changes can occur to drug molecule. The molecule active site of a drug can not correspond to the part of molecule which react in the physical-chemical testing. Therefore little changes can occur in the molecule active site and the physical-chemical answer keeps normal or yet the degradation products can show high UV absorptivity, for example.

The UV spectra (200 to $400 \mathrm{~nm}$ ) of stressed samples were analyzed. Comparing the absorptions between samples and standards solutions, it is possible to realize that the fluconazole UV absorption was increased (Table 6).

The ultraviolet spectrum of these samples showed the absorbance was increased after stress testing. The absorbance was increased about $12 \%$ to sample under dry heat for 60 days; $10 \%$ to sample under humid heat for 90 days; 24 and 27\% to samples under UVC for 66 and 180 days, respectively, at $261 \mathrm{~nm}$. These results are in agreement with those showed by Marciniec and coworkers [10] to fluconazole samples irradiated with ionized radiation.

The results indicate that the most adverse conditions to fluconazole stability are an oxidative medium, UVC-254 radiation and elevated temperature. Temperature is one of the most important environmental factors involved in drug degradation and cannot be controlled by the packaging [21].

\section{Conclusion}

For routine quality control of medicines, it is essential to employ 
Citation: Corrêa JCR, Reichman C, Soares CDV, Salgado HRN (2011) AStability Study of Fluconazole Applying Validated Bioassay and StabilityIndicating LC Methods. J Anal Bioanal Techniques 2:126. doi:10.4172/2155-9872.1000126

well-characterized, fully validated analytical methods to obtain reliable results that can be satisfactorily interpreted. The proposed methods were used successfully to investigate the fluconazole in stability tested conditions. Both methods are simple and efficient stability-indicating and they were validated showing accurate, specificity, robustness, excellent linearity and precision characteristics.

Our study leads to conclude that UV absorption cannot be used alone to quantify fluconazole in stability studies since it presents low selectivity. The bioassay testing may be more suitable for testing of fluconazole stability because it can determine the pharmaceutical activity of drugs; however it is not a separation method, and it cannot show the emergence of degradation products, then the LC method should be recommended along with the bioassay.

In addition, the results suggest that fluconazole must be maintained in strictly controlled conditions since its instability leads to decrease its therapeutic activity. The quality of fluconazole and its stability should be ensured to prevent the emergence of microbial resistance. Even more considering that fluconazole has had treatment failure [22]. In other hand, the extensive degradation of fluconazole in an oxidative medium when under high temperature and UVC exposure suggests that it can be inactivated by this way before being discarded, in order to avoid the development of microbial resistance.

\section{Acknowledgements}

The authors wish to thank the pharmaceutical company EMS (Brazil) for the supply of the raw material and thank the Fapesp, CNPq and PADC - UNESP to financial support.

\section{References}

1. Moreno AH, Silva MFC, Salgado HRN (2009) Stability study of azithromycin in ophthalmic preparations. Braz J Pharm Sci 45: 219-226.

2. Adams AlH, Gosmann G, Schneider PH, Bergold AM (2009) LC stability studies of voriconazole and structural elucidation of its major degradation product. Chromatographia 69: 115-122.

3. Kovaríkova P, Mokry M, Klimes J (2003) Photochemical stability of nimesulide. J Pharm Biomed Anal 31: 827-832.

4. Grant SM, Clissold SP (1990) Fluconazole: a review of its pharmacodynamic and pharmacokinetic properties and therapeutic potential in superficial and systemic mycoses. Drugs 39: 877-916.

5. Dash AK, Elmquist WF (2001) Fluconazole. In: Brittain HG (Ed.), Analytica profiles of drug substances and excipients, Academic Press, San Diego, 27: 67-113.
6. O'neil MJ (2006) The Merck Index - An Encyclopedia of Chemicals, Drugs, and Biologicals. (14thedn), Merck \& Co., New Jersey.

7. Pereira DG (2007) Importância do metabolismo no planejamento de fármacos Quím Nova 30: 171-177.

8. Dentinger PJ, Swenson CF (2009) Stability of reconstituted fluconazole ora suspension in plastic bottles and oral syringes. Ann Pharmacother 43: 485-489.

9. Yamreudeewong W, Lopez-Anaya A, Rappaport H (1993) Stability of fluconazole in an extemporaneously prepared oral liquid. Am J Hosp Pharm 50: 2366-2367.

10. Marciniec B, Dettlaff K, Jaroszkiewicz E, Bafeltowskac J (2007) Radiochemica stability of fluconazole in the solid state. J Pharm Biomed Anal 43: 1876-1880.

11. Correa JCR, Salgado HRN (2011) Review of fluconazole properties and analytical methods for its determination, Critical Review in Analytical Chemistry 41: 124-132.

12. ICH Guideline Q2 (R1) (2005) Validation of Analytical Procedures: Text and Methodology.

13. Youden WJ, Steiner EH (1975) Statistical Manual of AOAC - Association of Official Analytical Chemistry. Washington.

14. Hewitt W (1977) Microbiological assay. Academic Press, New York.

15. César IC, Pianetti GA (2009) Robustness evaluation of the chromatographic method for the quantitation of lumefantrine using Youden's test. Brazilian Journal of Pharmaceutical Sciences 45: 235-240.

16. Paim CS, Führ F, Barth AB, Gonçalves CEI, Nardi N, et al. (2011) Gemifloxacin mesylate (GFM) stability evaluation applying a validated bioassay method and in vitro cytotoxic study. Talanta 83: 1774-1779.

17. The United States Pharmacopoeia (2009) United States Pharmacopoeia Convention (32ndedn), Rockville, MD.

18. Farmacopéia Brasileira (1988) Agência Nacional de Vigilância Sanitéria (4thedn), Atheneu, São Paulo.

19. European Pharmacopoeia (2005) European Directorate for the Quality of Medicines (5thedn), Strasbourg Cedex, France.

20. ICH Guideline Q1A (R2) (2003) Stability testing of new drug substances and products.

21. Kommanaboyina B, Rhodes CT (1999) Trends in stability testing, with emphasis on stability during distribution and storage. Drug Dev Ind Pharm 25: 857 868.

22. Blumberg HM, Hendershot EF, Lott TJ (1992) Persistence of the same Candida albicans strain despite fluconazole therapy: Documentation by pulsed-field ge electrophoresis. Diagn Microbiol Infect Dis 15: 545-547.

\section{Submit your next manuscript and get advantages of OMICS} Group submissions

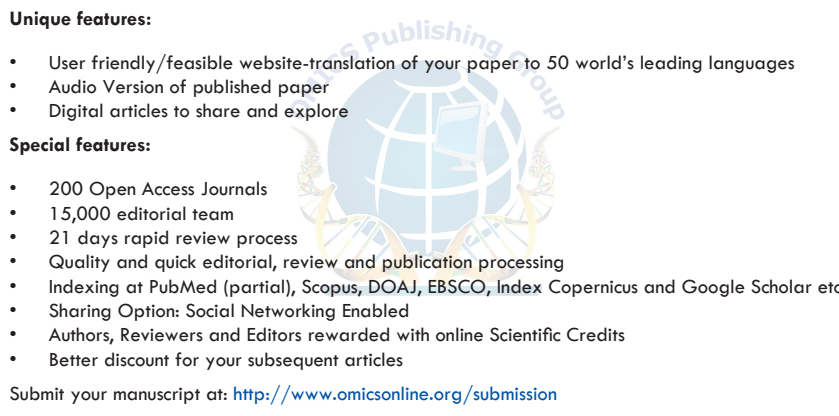

